\title{
A Simple and Easily Reproducible Model of Reversible Obstructive Jaundice in Rats
}

\author{
SEIGO HIRATANI, RYUTARO MORI, YOHEI OTA, RYUSEI MATSUYAMA, \\ TAKAFUMI KUMAMOTO, YOJI NAGASHIMA, DAISUKE MORIOKA and ITARU ENDO \\ Department of Gastroenterological Surgery, \\ Yokohama City University Graduate School of Medicine, Yokohama, Japan
}

\begin{abstract}
Background/Aim: Cholangiocarcinoma and pancreatic carcinoma are major malignancies that cause obstructive jaundice (OJ). This study aimed to develop a simple and easily reproducible rat model of reversible OJ (ROJ). Materials and Methods: OJ was induced by clamping the common bile duct (CBD) using a $U$-shaped titanium hemoclip and its base was attached by ligation using 2-cm long 4-0 polypropylene suture. An anti-adhesive sheet was placed around the CBD. OJ was mitigated by pulling the suture to remove the clip under laparotomy 3 days later. Serum chemistry and liver histopathology were compared between the ROJ group and sham surgery (SH) groups. Results: Three days after inducing $O J$, serum total bilirubin, aspartate aminotransferase, and alanine aminotransferase were remarkably elevated in the ROJ group and thereafter reduced significantly after mitigating OJ. Similar findings were confirmed by histopathology. Conclusion: Our rat model of reversible $O J$ was considered simple and easily reproducible.
\end{abstract}

Cholangiocarcinoma (CCA) and pancreas head ductal adenocarcinoma (PDAC) are two major malignancies that cause obstructive jaundice (OJ). Although surgery has been regarded as a sole modality which can provide a chance of cure for patients with these disease entities, only unsatisfactory outcome has been obtained by surgery alone $(1,2)$. Historically, the therapeutic value of preoperative biliary drainage (PBD) for these malignancies has been

This article is freely accessible online.

Correspondence to: Itaru Endo, MD, Ph.D., Department of Gastroenterological Surgery, Yokohama City University Graduate School of Medicine, 3-9 Fukuura, Kanazawa-Ku, Yokohama 2360004, Japan. Tel: +81 457872650, Fax: +81 457829161, e-mail: endoit@yokohama-cu.ac.jp

Key Words: Obstructive jaundice, bile duct ligation, reversible model, simple animal model. uncertain (3). Although surgery after the eradication of OJ by PBD was considered reasonable, delayed surgery because of awaiting mitigation of $\mathrm{OJ}$ and/or comorbidity caused by the PBD itself can be an obstacle for applying straightforward surgery and furthermore considered one of the factors leading to dismal surgical outcomes (4). Therefore, based on the uncertain therapeutic value of the PBD, most surgical animal models of OJ were irreversible OJ models (5-9).

On the contrary, recent advancements in medical treatment for malignancies, including chemotherapy, have been remarkable (10). As a result, neoadjuvant chemotherapy (NAC) or conversion surgery after effective chemotherapy has been gaining clinical relevance even in surgery for CCA or PDAC and thus vigorously performed recently $(11,12)$. In the setting of NAC or chemotherapy aiming at conversion surgery for CCA or PDAC, most chemotherapeutic agents cannot be administered under the condition of $\mathrm{OJ}$; thus, biliary drainage is a prerequisite for cases exhibiting OJ (3, 13-15). In such circumstances, animal models of reversible OJ are strongly demanded for basic research on the effect of resolved OJ on subsequent chemotherapy and/or surgery. Reversible OJ models require a two-stage surgery in principle, i.e., induction and mitigation of OJ $(16,17)$. Rats are known to have higher endurance to surgical stress than mice (18). Furthermore, transgenic rats have recently become technologically and/or commercially available (19). Therefore, rats are considered more suitable for producing a reversible OJ model than mice, for which the transgenics have long been established and commercially available (19).

Several reports on rat models of reversible OJ exist (16, 17, 20-29). The reports emphasized the simplicity of their methods. However, cutting and diverting or ligation and cannulation techniques reported by Costa et al. and Huang et al. were considered to require markedly refined surgical techniques $(28,29)$. The "common bile duct ligation with splint" technique reported by Oruc et al. was simple and excellent but used self-made elaborate material (20). Meanwhile, Kirkland et al. (30) reported an excellent method to induce reversible OJ in mice using a metal clip 
A
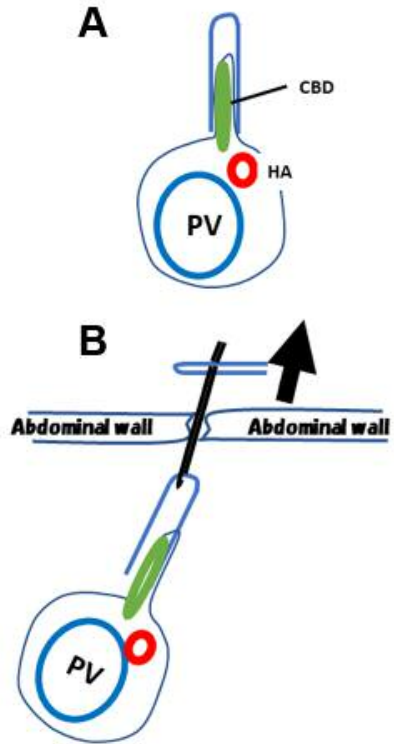

C
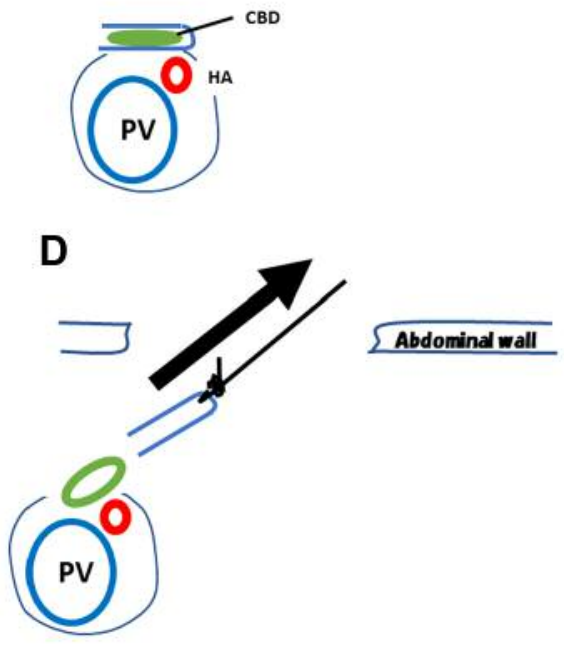

Figure 1. Difference between Kirkland's method and our method. In the training phase of this model, we recognized that the perception of the clip was very difficult at the second laparotomy because of the adhesion around the common bile duct (CBD). Furthermore, the removal of the clip was markedly troublesome even if the clip was perceived. Therefore, we added the following modification: 4-0 polypropylene monofilament suture was ligated at the bottom of the U-shaped clip and cut $2 \mathrm{~cm}$ from the ligation for subsequent pulling-off use. In the Kirkland method, a suture incorporated with the clip was merely sandwiched by the clip but not ligatured.

incorporated with a suture. However, this method (30) required some expertise due to the complexity introduced by the usage of mice. In Kirkland et al.'s method (30), the CBD was not isolated before clip clamping to avoid unintended injury around the CBD. Furthermore, they exteriorized both ends of the suture incorporated with the clip from the abdomen to remove the clip by pulling the ends outside the abdomen without the need for laparotomy at the second surgery (Figure 1). With such inventiveness, they avoided laparotomy for clip removal and succeeded to reduce morbidity. However, we considered that the relatively low success rate in their model was attributed to the avoidance of either CBD isolation or laparotomy for removing clip. In the present study, we aimed to improve the method by Kirkland et al. (30) to develop a rat model of reversible OJ, using only commercially available materials, which we consider was simple and thus easily reproducible.

\section{Materials and Methods}

This study protocol was approved by the Animal Ethics Committee of the Yokohama City University (protocol No. 000102). During all experimental procedures, the animals were treated in accordance with the Animal Protection Guidelines of Yokohama City University Graduate school of Medicine and the National Institutes of Health (https://oacu .oir.nih.gov/animal-research-advisory-committeeguidelines).
Animals. Seven-week-old male Wistar rats weighing 200-250 g (Oriental Yeast Co. Ltd. Tokyo, Japan) were used. Rats were fed with standard rat chow and tap water ad libitum under a 12-h light-dark cycle at $24^{\circ} \mathrm{C}$. They were fasted for $12 \mathrm{~h}$ before operation and given free access to $10 \%$ glucose water for $12 \mathrm{~h}$ after the operation. Thereafter, they were fed with standard rat chow and tap water ad libitum.

Operation procedures. The animals were anesthetized with inhalation of diethyl ether, placed in a supine position after being shaved free of hair on the abdomen, and then weighed. Thereafter, rats were anesthetized using a mixture of isoflurane gas and oxygen. The operation was performed under sterile condition.

Pararectal incision was made. After entering the abdominal cavity, the common bile duct (CBD) was identified by applying gentle caudal traction on the stomach and duodenum. Reversible OJ was achieved by two-stage surgery: OJ was induced by clamping the CBD using a $2.5 \mathrm{~mm}$ titanium clip (Weck Hemoclip ${ }^{\circledR}$, Teleflex, Wayne, PA) (Figure 2) at the first surgery and subsequently mitigated by removing the clip at the second surgery. Unlike the method by Kirkland et al. (30), we isolated the CBD gently before clamping. In addition, we performed laparotomy in the second surgery to remove the clip (Figure 1). However, in the training phase of this model, we recognized that the perception of the clip was very difficult at the second laparotomy because of the adhesion around the CBD. Furthermore, clip removal was markedly troublesome even if the clip was perceived. Therefore, we added the two following modifications. First, 4-0 polypropylene monofilament suture was ligated at the bottom of the U-shaped clip and cut at $2 \mathrm{~cm}$ from the ligation for subsequent pulling-off use (Figure 2). In the method of Kirkland et al. (30), a suture 


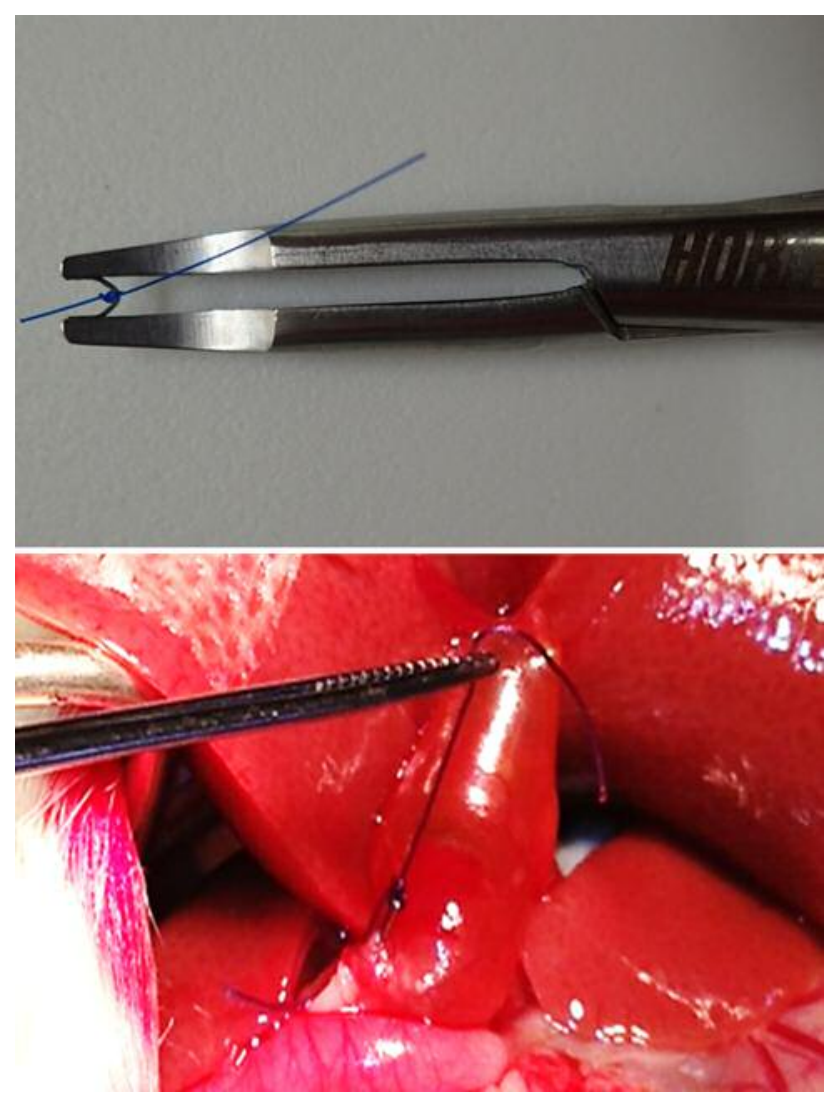

Figure 2. Our modifications to the Kirkland method. In the training phase of this model, we recognized that the perception of the clip was very difficult at the second laparotomy because of the adhesion around the common bile duct (CBD). Furthermore, clip removal was markedly troublesome even if the clip was perceived. Therefore, we added the two following modifications. First, 4-0 polypropylene monofilament suture was ligated at the bottom of the U-shaped clip and cut at $2 \mathrm{~cm}$ from the ligation for subsequent pulling-off use (upper half). In the Kirkland method, a suture incorporated with the clip was merely sandwiched by the clip, but not ligated. Second, bioresorbable hyaluronic acid/carboxymethylcellulose membrane (Seprafilm ${ }^{\circledR}$, Genzyme, Cambridge, MA, USA) was used. We placed it on the intra-abdominal surgical site before closing the abdomen with a 4-0 silk running suture at the first surgery. With these two modifications, the clip was easy to perceive and remove at the second surgery.

incorporated with the clip was merely sandwiched by the clip but not ligatured. Second, bioresorbable hyaluronic acid/carboxymethylcellulose membrane (Seprafilm, Genzyme, Cambridge, MA, USA) was used. We placed it on the intraabdominal surgical site before closing the abdomen with 4-0 silk running suture at the first surgery. With these two modifications, the clip became easy to perceive and remove at the second surgery. Three days after the first surgery for inducing OJ, under the anesthesia method, the rats underwent midline laparotomy and the clips were removed by pulling the ligated suture with gentle counter traction to avoid surrounding tissue injury (Figure 2).
The sham surgery ( $\mathrm{SH}$ ) group underwent the two-stage procedure almost similar to the ROJ group, except for the CBD clipping and de-clipping.

Experimental design. To confirm the reliability of our model, the first 30 rats receiving reversible OJ procedures were used for survival analysis. Then, 56 rats were divided into the two groups (28 for each group), i.e., SH and reversible OJ (ROJ) groups. Seven of each group were sacrificed under anesthesia with diethyl ether at the following time points for blood and liver sampling: immediately (day 0), 3 days (day 3), 5 days (day 5), and 7 days (day 7) after the first surgery. On day 3 , rats were sacrificed without removing the clip in the ROJ group.

Biochemical assays. The blood samples were obtained by cardiac puncture and immediately centrifuged by $3,000 \mathrm{rpm}$ for $10 \mathrm{~min}$ under $4^{\circ} \mathrm{C}$ temperature for extracting the serum. Serum levels of total bilirubin (T-bil) and direct bilirubin (D-bil), aspartate aminotransferase (AST), and alanine aminotransferase (ALT) were measured using standard laboratory methods.

Histological analysis of the liver. Under anesthesia, the liver was rapidly removed and fixed with $10 \%$ formaldehyde in phosphatebuffered saline. Paraffin-embedded liver sections of 3- $\mu$ m thickness were stained with hematoxylin-eosin and evaluated by the pathologist (Y.N).

Statistical analysis. Numerical variables were expressed as mean ( \pm standard deviation) and compared using the Student's $t$-test. All statistical analyses were performed using IBM SPSS Statistics version 23 (IBM, Armonk, NY, USA). Two-tailed $p$-values $<0.05$ were considered statistically significant.

\section{Results}

Intraoperative findings of the second surgery and postoperative courses. The liver had a dark-yellowish color and was apparently swollen. The extrahepatic bile duct proximal to the clip was markedly dilatated in the ROJ group. These findings suggested that OJ was properly induced by the clip. Furthermore, the dilatation of the CBD proximal to the clip was mitigated immediately after removing clip in the ROJ group.

Of the 30 rats, two rats used for survival analysis died after the second surgery. One of the two died of intraabdominal bleeding 2 days after the second surgery, and the remaining rat died of biliary peritonitis 4 days after the second surgery, respectively. These two deaths were observed in the first 10 of the 30 rats and the remaining 28 rats survived for more than a month. Four rats were randomly selected from the 28 surviving rats and were sacrificed for assessing the intra-abdominal findings and the liver histopathology more than 1 month after the second surgery. Any morbidity was not observed in these rats, and their liver showed a normal histopathology. Accordingly, the mortality as well as morbidity rate was $6.7 \%$. 

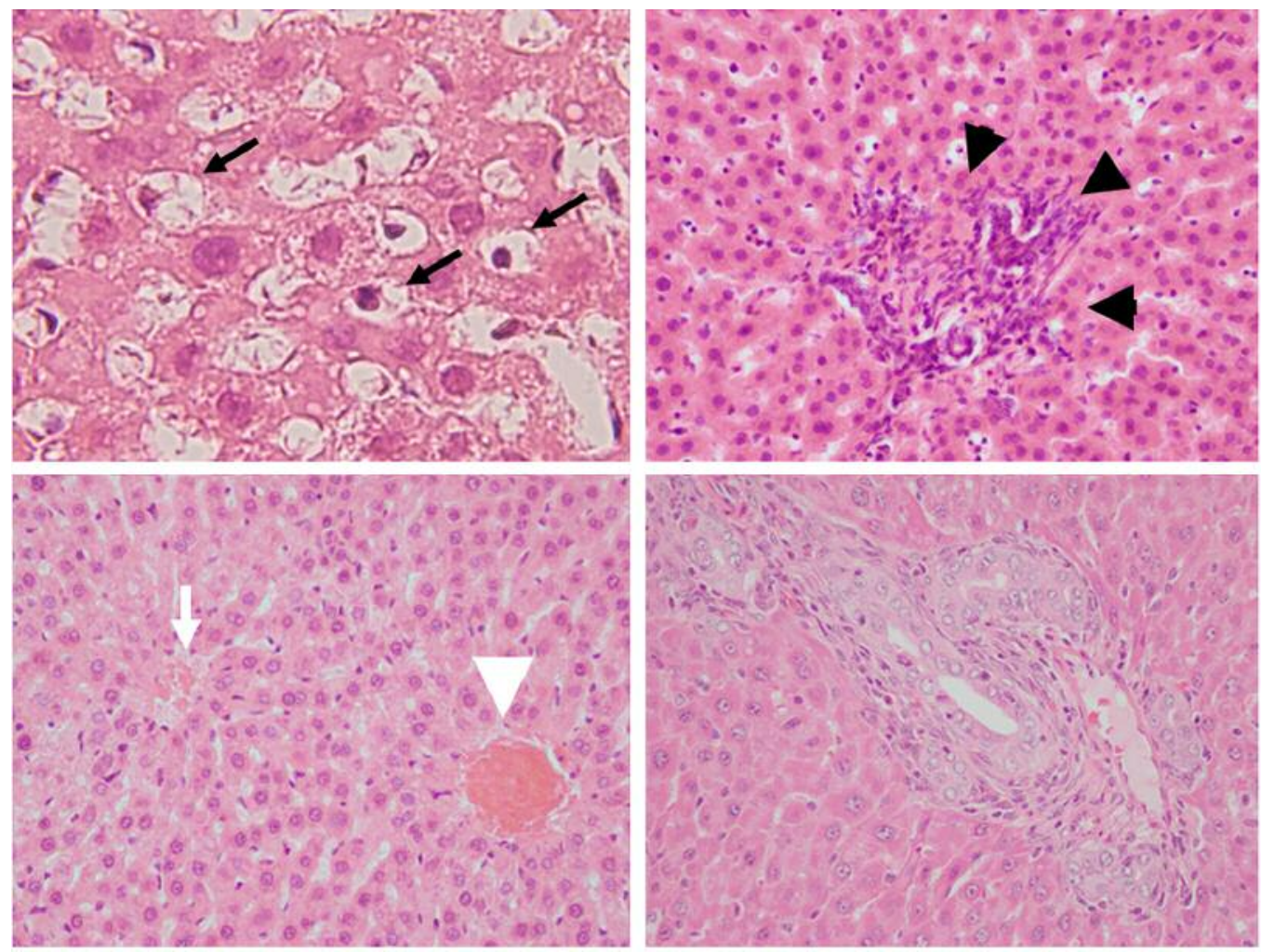

Figure 3. Histological findings of the liver in the reversible obstructive jaundice group, 3 days after clamping the common bile duct. In the reversible obstructive jaundice (ROJ) group, hepatocyte ballooning (upper left, small black arrows) due to ductular (lower left, white arrow) and intracytoplasmic (lower left, white arrowhead) cholestasis was remarkable on day 3. Furthermore, expansion of the portal area due to inflammatory cell infiltration and pseudo bile duct proliferation was notable (upper right, small black arrowheads). Mild lobular inflammation was sporadically identified (lower right).

Chronological changes in serum liver function tests. None of the 56 rats used for data collection died before each designed time point. In the SH group, serum liver function test results showed nearly no changes throughout the study period. In contrast, relevant chronological changes of serum liver function tests were observed in the ROJ group. Remarkable elevation of T-bil, D-bil, AST, and ALT on day 3 was found in the ROJ group (Table I). These values continued to reduce significantly after the second surgery (day 3) by day 7 in the ROJ group, although comparison of these values between the $\mathrm{SH}$ and ROJ groups showed that these values were significantly greater in the ROJ group than in the SH group either on day 5 or day 7. In other words, OJ was properly induced by clamping the CBD and mitigated by removing the clip although OJ was not completely eradicated by day 7 .

Histological findings during inducing and releasing $O J$. In the ROJ group, hepatocyte ballooning due to ductular and intracytoplasmic cholestasis was remarkable on day 3 . Furthermore, expansion of the portal area due to inflammatory
Table I. Comparison of serum liver function tests between the sham surgery and reversible obstructive jaundice groups.

\begin{tabular}{crrc}
\hline & $\begin{array}{c}\text { SH group } \\
\text { ( } \mathrm{n}=7 \text { at each } \\
\text { time point })\end{array}$ & $\begin{array}{r}\text { ROJ group } \\
\text { ( } \mathrm{n}=7 \text { at each } \\
\text { time point) }\end{array}$ & $p$-Value \\
\hline T-bil on & & & \\
Day 0 & $0.054 \pm 0.017$ & $0.049 \pm 0.013$ & 0.356 \\
Day 3 & $0.0067 \pm 0.012$ & $6.8 \pm 0.60$ & $<0.001$ \\
Day 5 & $0.024 \pm 0.0043$ & $0.36 \pm 0.12$ & $<0.001$ \\
Day 7 & $0.017 \pm 0.014$ & $0.13 \pm 0.028$ & $<0.001$ \\
AST on & & & \\
Day 0 & $129.42 \pm 40.49$ & $111.86 \pm 39.54$ & 0.24 \\
Day 3 & $52.83 \pm 9.83$ & $490.67 \pm 224.38$ & 0.005 \\
Day 5 & $43.86 \pm 7.78$ & $99.57 \pm 44.28$ & 0.015 \\
Day 7 & $43.71 \pm 7.06$ & $46.71 \pm 12.09$ & 0.62 \\
ALT on Day 0 & $22.14 \pm 3.24$ & $23.86 \pm 2.54$ & 0.36 \\
Day 3 & $6.00 \pm 0.89$ & $145.17 \pm 65.86$ & 0.003 \\
Day 5 & $9.29 \pm 2.29$ & $39.57 \pm 16.14$ & 0.004 \\
Day 7 & $8.29 \pm 1.98$ & $18.29 \pm 7.04$ & 0.008 \\
\hline
\end{tabular}

ALT: Alanine aminotransferase; AST: aspartate aminotransferase; ROJ: reversible obstructive jaundice; SH: sham surgery; T-bil: total bilirubin. 

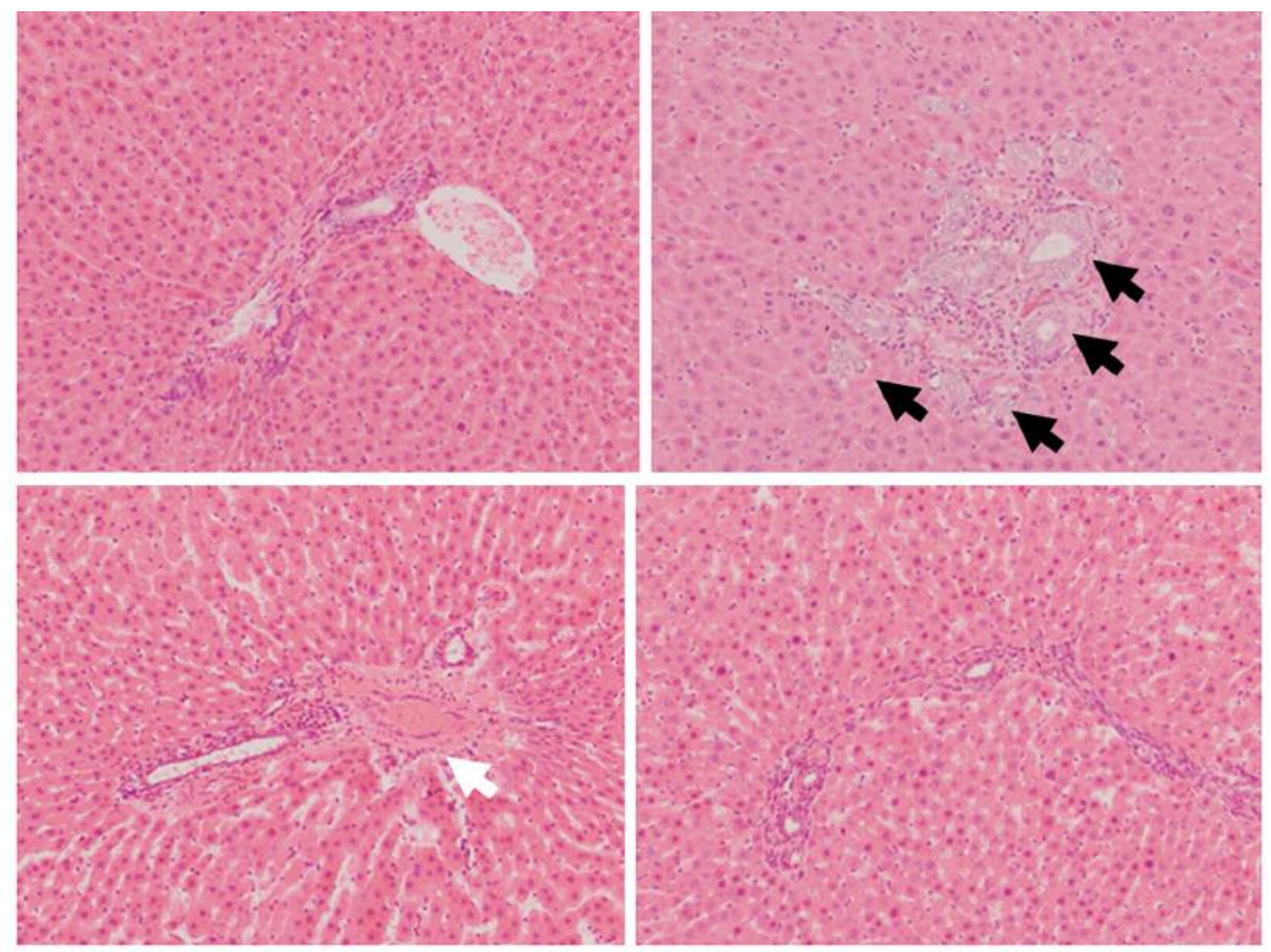

Figure 4. Histological findings of the liver in the reversible obstructive jaundice group on day 5 (i.e., 2 days after clip removal). On day 5, findings of cholestasis were markedly relieved, but sinusoidal dilatation accompanied by hepatocyte atrophy was noticeable. Expansion of the portal area remained, but was less remarkable than that on day 3. On day 7, sinusoidal dilatation, hepatocyte atrophy, and expansion of the portal area, including cell infiltration and pseudo bile duct proliferation, were obviously mitigated, but not completely eradicated.

cell infiltration and pseudo bile duct proliferation was notable. Mild lobular inflammation was sporadically identified (Figure 3 ). On day 5, i.e., 2 days after removing the clip, findings of cholestasis were markedly relieved. Instead, sinusoidal dilatation accompanied by hepatocyte atrophy was noticeable (Figure 4). Expansion of the portal area remained but was less remarkable than that on day 3 . On day 7 , sinusoidal dilatation, hepatocyte atrophy, and expansion of the portal area, including cell infiltration and pseudo bile duct proliferation, were obviously mitigated but not completely eradicated.

\section{Discussion}

In the current era, when NAC or conversion surgery after effective chemotherapy has been gaining wider acceptance, the basic research for investigating various effects of resolved OS on subsequent chemotherapy and/or surgery is considered very important. Hence, we attempted to acquire previously reported techniques for reversible OJ animal models $(16,17,20-29)$. Our group has reported the results of several studies using various animal hepatectomy and/or liver transplantation models (31-40); thus, we recognized that our group has sufficient skill to reproduce these models. However, we could not reproduce these models. Hence, this necessitated the development of a simpler and more easily reproducible animal model of reversible OJ.

The CBD ligation rat model used to induce OJ was a simple, easily reproducible, and thus an excellent method even if it is irreversible in principle (20). We considered that the most noteworthy result of this method is the unnecessariness of particular expertise in surgery. Thus, following the method reported by Kirkland et al. (30), we replaced the ligation by clip clamping, which appeared easier to remove than the ligation. With some modifications, including 4-0 polypropylene suture attached to the clip for pulling off use and the use of Seprafilm, we succeeded to develop a reliable reversible OJ model in the present study. Mortality as well as morbidity rate with $6.7 \%$ was considered acceptable compared to those of previously reported methods (16, 17, 20-29). Furthermore, it was confirmed by either serum liver function tests or histopathology of the liver that OJ was properly induced and thereafter mitigated in our model. We could not reproduce any of the previously reported reversible OJ models in rats $(16,17,20-29)$. Nevertheless, we 
succeeded to develop this model. Hence, we consider that our model is simpler and more easily reproducible than the previously reported models.

We recognized several limitations in the present study. First, we investigated a single time point of removing the clip. In previous reports of reversible OJ rat models, mitigation of OJ was attempted on 7 days after the induction of $\operatorname{OJ}(20,26,29)$. Serum liver function tests and liver histopathology demonstrated that the OJ was properly induced on day 3 in our model. Furthermore, in our previous report regarding the repeat major hepatectomy model in rats, in which the second major hepatectomy was performed 7 days after the first major hepatectomy (38), we confirmed that the second laparotomy within at least 7 days after the first laparotomy can be performed quite safely using Seprafilm. Hence, we consider that the present model can be reproduced, with the second surgery, for mitigating OJ, performed at other time points. Second, the CBD appeared to recover to the normal physiological condition after the clip removal in our reversible OJ model. This was suggested by the fact that the livers of four sacrificed rats, among the 28 surviving ones in the survival analysis, showed a normal histopathology, in which the OJ was completely eradicated. In other words, long-term cholestasis cannot be assessed in our model. In the clinical setting where the PBD is applied to patients with CCA or PDAC exhibiting OJ, mild to moderate cholestasis often remains due to an unphysiological biliary drainage route of the PBD and/or the presence of malignancy itself even though the PBD would be properly applied (41). Such remaining cholestasis often affects the subsequent clinical course disadvantageously. Recently, Aoki et al. (42) reported a murine model of long-term cholestasis caused by CBD stenosis, which was simple and thus reliable. We consider that incorporation of our reversible OJ model and the model reported by Aoki et al. (42) appears less stressful and enables precise simulation in the clinical setting of the OJ mitigated by the PBD. As such, the biggest advantage of our reversible OJ model is perhaps its simplicity, and its incorporation with other surgical models appears easy.

\section{Conclusion}

In conclusion, we developed a simple and reliable model of reversible OJ in rats. Our model can be easily incorporated with other surgical models because of its simplicity. Therefore, we consider that our model is applicable to various settings of the OJ.

\section{Conflicts of Interest}

The Authors reported no proprietary or commercial interest in any product mentioned or concept discussed in this article.

\section{Authors' Contributions}

Ryutaro Mori, Yohei Ota, Ryusei Matsuyama, Takafumi Kumamoto, contributed to this work with conception and design of the study; Yoji Nagashima contributed to this work with histological analysis; Daisuke Morioka, and Itaru Endo contributed to this work with data evaluation, drafting, and final approval of the article.

\section{References}

1 Jarnagin WR, Fong Y, DeMatteo RP, Gonen M, Burke EC, Bodniewicz BSJ, Youssef BAM, Klimstra D and Blumgart LH: Staging, resectability, and outcome in 225 patients with hilar cholangiocarcinoma. Ann Surg 234: 507-517, 2001. PMID: 11573044.

2 Conlon KC, Klimstra DS and Brennan MF: Long-term survival after curative resection for pancreatic ductal adenocarcinoma: Clinicopathologic analysis of 5-year survivors. Ann Surg 223: 273-279, 1996. PMID: 8604907.

3 van der Gaag NA, Rauws EA, van Eijck CH, Bruno MJ, van der Harst E, Kubben FJ, Gerritsen JJ, Greve JW, Gerhards MF, de Hingh IH, Klinkenbijl JH, Nio CY, de Castro SM, Busch OR, van Gulik TM, Bossuyt PM and Gouma DJ: Preoperative biliary drainage for cancer of the head of the pancreas. N Engl J Med 362: 129-137, 2010. PMID: 20071702. DOI: 10.1056/ NEJMoa0903230.

4 Sugawara G, Ebata T, Yokoyama Y, Igami T, Takahashi Y, Takara D and Nagino M: The effect of preoperative biliary drainage on infectious complications after hepatobiliary resection with cholangiojejunostomy. Surgery 153: 200-210, 2013. PMID: 23044266. DOI: 10.1016/j.surg.2012.07.032.

5 Lee KN, Yoon SK, Lee JW, Kim KN, Park BH, Kwak JY, Jeong JS and Kim YH: Hepatopulmonary syndrome induced by common bile duct ligation in a rabbit model: Correlation between pulmonary vascular dilatation on thin-section CT and angiography and serum nitrite concentration or endothelial nitric oxide synthase (eNOS)1 expression. Korean J Radiol 5: 149, 2004. PMID: 15467411. DOI: 10.3348/kjr.2004.5.3.149.

6 Myers SI, Bartula LL, Colvin MP, Parkman HP, Braverman AA and Ruggieri MR: Bile duct ligation induced acute inflammation up-regulates cyclooxygenase-2 content and PGE2 release in guinea pig gallbladder smooth muscle cell cultures. Prostaglandins Leukot Essent Fatty Acids 72: 327-333, 2005. PMID: 15850713. DOI: 10.1016/j.plefa.2004.12.005

7 Myers SI, Haley-Russell D, Parks L and Husband K: Common bile duct ligation in rabbit: A new model of acute cholecystitis description of histology and bile analysis. J Surg Res 45: 556564, 1988. PMID: 3184929.

8 Aoki H, Aoki M, Yang J, Katsuta E, Mukhopadhyay P, Ramanathan R, Woelfel IA, Wang X, Spiegel S, Zhou H and Takabe K: Murine model of long-term obstructive jaundice. J Surg Res 206: 118-125, 2016. PMID: 27916350. DOI: 10.1016/ j.jss.2016.07.020

9 Tiao MM, Wang FS, Huang LT, Chuang JH, Kuo HC, Yang YL and Huang YH: MicroRNA-29a protects against acute liver injury in a mouse model of obstructive jaundice via inhibition of the extrinsic apoptosis pathway. Apoptosis 19: 30-41, 2014. PMID: 24052410. DOI: 10.1007/s10495-013-0909-4.

10 Suggitt $M$ and Bibby MC: 50 years of preclinical anticancer drug screening: Empirical to target-driven approaches. Clin Cancer Res 11: 971-981, 2005. PMID: 15709162. 
11 Kato A, Shimizu H, Ohtsuka M, Yoshidome H, Yoshitomi H, Furukawa K, Takeuchi D, Takayashiki T, Kimura F and Miyazaki M: Surgical resection after downsizing chemotherapy for initially unresectable locally advanced biliary tract cancer: a retrospective single-center study. Ann Surg Oncol 20: 318-324, 2013. PMID: 23149849. DOI: 10.1245/s10434-012-2312-8.

12 Suker M, Beumer BR, Sadot E, Marthey L, Faris JE, Mellon EA, El-Rayes BF, Wang-Gillam A, Lacy J, Hosein PJ, Moorcraft SY, Conroy T, Hohla F, Allen P, Taieb J, Hong TS, Shridhar R, Chau I, van Eijck CH and Koerkamp BG: FOLFIRINOX for locally advanced pancreatic cancer: a systematic review and patient-level meta-analysis. Lancet Oncol 17: 801-810, 2016. PMID: 27160474. DOI: 10.1016/S1470-2045(16)00172-8.

13 Field KM, Dow C and Michael M: Part I: Liver function in oncology: biochemistry and beyond. Lancet Oncol 9: 1092-1101, 2008. PMID: 19012858. DOI: 10.1016/S1470-2045(08)70279-1.

14 Field KM and Michael M: Part II: Liver function in oncology: towards safer chemotherapy use. Lancet Oncol 9: 1181-1190, 2008. PMID: 19038765. DOI: 10.1016/S1470-2045(08)70307-3.

15 Fukutomi A, Furuse J, Okusaka T, Miyazaki M, Taketsuna M, Koshiji $M$ and Nimura Y: Effect of biliary drainage on chemotherapy in patients with biliary tract cancer: an exploratory analysis of the BT22 study. HPB (Oxford) 14: 221-227, 2012. PMID: 22404259. DOI: 10.1111/j.1477-2574.2011.00431.x.

16 Posner MC, Burt ME, Stone MD, Han BL, Warren RS, Vydelingum NA and Brennan MF: A model of reversible obstructive jaundice in the rat. J Surg Res 48: 204-210, 1990. PMID: 2314093.

17 Aronson DC, Chamuleau RA, Frederiks WM, Gooszen HG, Heijmans HS and James J: Reversibility of cholestatic changes following experimental common bile duct obstruction: fact or fantasy? J Hepatol 18: 85-95, 1993. PMID: 8340613

18 Starkel P and Leclercq IA: Animal models for the study of hepatic fibrosis. Best Pract Res Clin Gastroenterol 25: 319-333, 2011. PMID: 21497748. DOI: 10.1016/j.bpg.2011.02.004.

19 Nohmi T, Masumura K and Toyoda-Hokaiwado N: Transgenic rat models for mutagenesis and carcinogenesis. Genes Environ 39: 11, 2017. PMID: 28174618. DOI: 10.1186/s41021-016-0072-6.

20 Oruc MT, Ozmen MM and Han U: A new technique for inducing and releasing obstructive jaundice in rats. Eur Surg Res 43: 354359, 2009. PMID: 19828959. DOI: 10.1159/000247061.

21 Yu JL, Wang LQ, Andersson R, Persson BG and Bengmark S: New model of reversible obstructive jaundice in rats. Eur J Surg 159: 163-166, 1993. PMID: 8102891.

22 Kato S, Nagano I, Nimura Y and Wakabayashi T: Hepatic recovery after biliary drainage in experimental obstructive jaundice complicated by biliary infection. Hepatogastroenterology 41: 217-221, 1994. PMID: 7959541.

23 Accatino L, Contreras A, Fernandez S and Quintara C: The effect of complete biliary obstruction on bile flow and bile acid excretion: postcholestatic choleresis in the rat. J Lab Clin Med 83: 706-717, 1979. PMID: 429869.

24 Hsien CS, Huang CC, Huang LT, Chung JC and Chou MH: Reversible cholestasis and cholangitis induced by biliary drainage and infusion in the rat. Eur Surg Res 38: 11-17, 2006. PMID: 16479128. DOI: 10.1159/000091480.

25 Melzer E, Krepel Z, Ronen I and Bar-Meir S: Recovery of hepatic clearance and extraction following a release of common bile duct obstruction in the rat. Res Exp Med (Berl) 192: 35-40, 1992. PMID: 1570412.
$26 \mathrm{Li} \mathrm{W}$ and Chung SC: An improved rat model of obstructive jaundice and its reversal by internal and external drainage. J Surg Res 101: 4-15, 2001. PMID: 11676548. DOI: 10.1006/ jsre.2001.6240.

27 Ker CG and Wu SG: A simple animal model for inducing and releasing surgical jaundice in rats. Gaoxiong Yi Xue Ke Xue Za Zhi 8: 520-524, 1992. PMID: 1296029.

28 Costa AM, Tuchweber B, Lamireau T, Yousef IM, Balabaud C, Rosenbaum $\mathrm{J}$ and Desmouliere A: Role of apoptosis in the remodeling of cholestatic liver injury following release of the mechanical stress. Virchows Arch 442: 372-380, 2003. PMID: 12715172. DOI: $10.1007 / \mathrm{s} 00428-003-0773-7$.

29 Huang X, Li CH, Zhang AQ, Kong Z and Dong JH: A simple rat model of in situ reversible obstructive jaundice in situ reversible obstructive jaundice model. Ann Surg Treat Res 92: 389-395, 2017. PMID: 28580342. DOI: 10.4174/ astr.2017.92.6.389.

30 Kirkland JG, Godfrey CB, Garrett R, Kakar S, Yeh BM and Corvera CU: Reversible surgical model of biliary inflammation and obstructive jaundice in mice. J Surg Res 164: 221-227, 2010. PMID: 19932898. DOI: 10.1016/j.jss.2009.08.010.

31 Kubota T, Takebe K, Yang M, Sekido H. Endo E, Ichikawa Y, Togo $\mathrm{S}$ and Shimada H: Minimum sizes for remnant and transplanted livers in rats. J Hep Bil Pancr Surg 4: 398-404, 1997. DOI: $10.1007 / \mathrm{BF} 02488972$.

32 Kamimukai N, Togo S, Hasegawa S, Kubota T, Kurosawa H, Li XK, Suzuki S and Shimada H: Expression of Bcl-2 family reduces apoptic hepatocytes after excessive hepatectomy. Eur Surg Res 33: 8-15, 2001. PMID: 11340266. DOI: 10.1159/ 000049686.

33 Morioka D, Watanabe K, Makino H, Saito S, Ueda M, Kubota T, Sekido H, Matsuo K, Ichikawa Y, Endo I, Togo S and Shimada H: Safety limit of the extent of hepatectomy for rats with moderately fatty liver: experimental study concerning living liver donor safety. J Gastroenterol Hepatol 21: 367-373, 2006. PMID: 16509860. DOI: 10.1111/j.1440-1746.2005.03972.x.

34 Morioka D, Kubota T, Sekido H, Matsuo K, Saito S, Ichikawa Y, Endo I, Togo S and Shimada H: Prostaglandin E1 improved the function of transplanted fatty liver in a rat reduced-size-liver transplantation model under conditions of permissible cold preservation. Liver Transpl 9: 79-86, 2003. PMID: 12514777. DOI: $10.1053 /$ jlts.2003.36845.

35 Morioka D, Kasahara M, Takada Y, Corrales JP, Yoshizawa A, Sakamoto S, Taira K, Yoshitoshi EY, Egawa H, Shimada H and Tanaka K: Living donor liver transplantation for pediatric patients with inheritable metabolic disorders. Am J Transpl 5: 2754-2763, 2005. PMID: 16212637. DOI: 10.1111/j.16006143.2005.01084.x.

36 Matsuo K, Togo S, Sekido H, Morita T, Kamiyama M, Morioka D, Kubota T, Miura Y, Tanaka K, Ishikawa T, Ichikawa Y, Endo I, Goto H, Nitanda H, Okazaki Y, Hayashizaki Y and Shimada H: Pharmacologic preconditioning effects: Prostaglandin E1 induces heat-shock proteins immediately after ischemia/reperfusion of the mouse liver. J Gastrointest Surg 9: 758-768, 2005. PMID: 15985230. DOI: 10.1016/j.gassur.2005.02.004.

37 Makino H, Togo S, Kubota T, Morioka D, Morita T, Kobayashi T, Tanaka K, Shimizu T, Matsuo K, Nagashima Y and Shimada $\mathrm{H}$ : A good model of hepatic failure after excessive hepatectomy in mice. J Surg Res 127: 171-176, 2005. PMID: 15916769. DOI: 10.1016/j.jss.2005.04.029. 
38 Saito S, Togo S, Morioka D, Matsuo K, Yoshimoto N, Nagano Y, Tanaka K, Kubota T, Nagashima Y and Shimada H: A rat model of a repeat 70\% major hepatectomy. J Surg Res 134: 322326, 2006. PMID: 16519902. DOI: 10.1016/j.jss.2006.01.008.

39 Watanabe K, Togo S, Takahashi T, Matsuyama R, Yamamoto H, Shimizu T, Makino H, Matsuo K, Morioka D, Kubota T, Nagashima $\mathrm{Y}$ and Shimada H: PAI-1 plays an important role in liver failure after excessive hepatectomy in rat. J Surg Res 143: 13-19, 2007. PMID:17655862. DOI: 10.1016/j.jss.2007.04.041.

40 Kawaguchi D, Hiroshima Y, Kumamoto T, Mori R, Matsuyama $\mathrm{R}$, Ichikawa $\mathrm{Y}$, Inayama $\mathrm{Y}$ and Endo I: Effect of portal vein ligation plus venous congestion on liver regeneration in rats. Ann Hepatol 18: 89-100, 2018. PMID: 30596629. DOI: $10.5604 / 01.3001 .0012 .7866$.
41 Fiori E, Macchiarelli G, Schillaci A, Lamazza A, Burza A, Paparelli C, Cavallaro A and Cangemi V: Hepatocyte ultrastructural aspects after preoperative biliary drainage in pancreatic cancer patients with cholestatic jaundice. Anticancer Res 23: 4859-4863, 2003. PMID: 14981936.

42 Aoki H, Aoki M, Yang J, Katsuta E, Mukhopadhyay P, Ramanathan R, Woelfel IA, Wang X, Spiegel S, Zhou H and Takabe K: Murine model of long-term obstructive jaundice. J Surg Res 206: 118-125, 2016. PMID: 27916350. DOI: 10.1016/ j.jss.2016.07.020.

Received January 20, 2019

Revised February 6, 2019

Accepted February 8, 2019 